\title{
Evaluation of F-wave study in assessment of neuropathy among hypothyroid patients with or without clinical neuro deficit- A case control study
}

\author{
Satyendra K. Prajapati ${ }^{1, *}$, Balaji W. Ghugare ${ }^{2}$, Mukesh R. Dinkar ${ }^{3}$ \\ ${ }^{1}$ Associate Professor, ${ }^{2}$ Assistant Professor, ${ }^{3}$ Professor \& HOD, Dept. of Physiology, ${ }^{1}$ Government Medical College, Jagdalpur, \\ Chattisgarh, ${ }^{2,3}$ GMERS Medical College, Gotri, Vadodara, Gujarat, India
}

*Corresponding Author:

Email: drsachinprajapati@gmail.com

Received: $10^{\text {th }}$ February, 2018

Accepted: $14^{\text {th }}$ March, 2018

\begin{abstract}
Introduction: Nerve conduction studies (NCS) assess neuropathy in thyroid dysfunction. Entrapment neuropathies and general sensorimotor polyneuropathies are often diagnosed in these patients. F waves are usually prolonged in generalized and entrapment neuropathies. Hypothyroid patients often present with carpel tunnel syndrome. Objective: To evaluate and compare $\mathrm{F}$ wave study variables in hypothyroid patients with normal subjects. To assess neuropathies in hypothyroid patients, by using Fwave study as an independent test.

Materials and Methods: 23 hypothyroid and 23 normal participants were selected according to selection criteria underwent $\mathrm{F}$ wave study. Variables like F wave minimum, maximum and mean latencies were obtained from control and cases. Data was analyzed with Statistical Package for Social Sciences (SPSS) 10.0 version. Unpaired t'test was used to evaluate significant difference between cases and controls if any. $\mathrm{P}$ value $<0.05$ was considered statistically significant.

Results: F wave study variables of 23 (twenty Three) hypothyroid cases were compared with 23 (twenty three) age and sex matched controls. Statistically significant difference ( $\mathrm{p}$ value < 0.05 ) were observed between Median motor $\mathrm{F}$ wave minimum, maximum and mean latencies of control and cases. No significant difference was observed between Ulnar motor $\mathrm{F}$ wave minimum, maximum and mean latencies of control and cases ( $p$ value $>0.05$ ). Conclusion: Present study concluded that $F$ wave study may be used as an independent electrodiagnostic (EDX) test to assess median neuropathy at wrist in hypothyroid cases with or without clinical neurodeficit.
\end{abstract}

Keywords: Hypothyroid, Nerve conduction study, Carpel tunnel syndrome, polyneuropathy, F wave study.

\section{Introduction}

Thyroid hormones are involved in many functions of the central and peripheral nervous system. Different neurological signs and symptoms are observed depending on its deficiency or excess. ${ }^{1}$ In Thyroid dysfunction, associated prevalence of neuromuscular disorders has been reported to be between 20-80 \%. ${ }^{2}$ Diffuse peripheral neuropathy is very common in thyroid dysfunction, but due to paucity of precise diagnostic criteria its prevalence could not be properly estimated and hence remains variable from study to study. ${ }^{3}$ The thyroid hormone affects the central and peripheral nervous systems via its role in gene expression, myelin production, its effects on the neurotransmitter system and axonal transportation. ${ }^{4}$

Literature suggests that electrophysiological evaluation of hypothyroid patients i.e. nerve conduction studies showed abnormalities in its different variables. Motor nerve conduction study (MNCS), sensory nerve conduction study (SNCS), Visual evoked potential (VEP), Blink reflex and late responses variables were seen affected in thyroid dysfunction. Prevalence of electrodiagnostic (EDX) abnormalities concluded to have entrapment, and /or sensorimotor polyneuropathies among hypothyroids. ${ }^{5,6} \mathrm{~F}$ wave study is one of the late responses studied and interpreted in association with routine nerve conduction findings. Normally F wave minimum latencies are higher in ulnar motor nerves as compared to median motor nerves depending on length of nerves. In median neuropathy at wrist often median $\mathrm{F}$ wave minimum latencies are prolonged as compared to Ulnar. Thus it contributes in diagnosis of entrapment neuropathy. ${ }^{7}$ With above background present study was designed to explore the role $\mathrm{F}$ wave study as an independent variable to assess median neuropathy at wrist among newly diagnosed hypothyroid patients with or without clinical evidence of carpel tunnel syndrome.

\section{Material and Methods}

Present case-control study was conducted at clinical neurophysiology laboratory in department of physiology in a tertiary health care teaching centre during January 2014 to December 2017. Study was approved by the Institutional Human Ethics Committee. Written informed consent was taken in vernacular language in the structured format from all the participants and the study was carried out in accordance with the World Medical Association Declaration of Helsinki. 


\section{Selection of cases and controls Inclusion Criteria:}

Twenty three (23) newly diagnosed hypothyroid cases were selected following strict inclusion and exclusion criteria. Cases that showed serum TSH level above $4.12 \mathrm{mIU} / \mathrm{L}$ were labelled hypothyroid and included in study. ${ }^{8}$

Age and sex matched controls were selected from hospital staff and relatives of patients without any history of recent illness, or neurological symptoms and signs. Serum TSH levels were confirmed to be in normal range (euthyroid).

Exclusion criteria: Those cases with H/O hypertension, diabetes, pregnancy, musculoskeletal disorders, neuromuscular disorders, developmental disorders, and alcohol abuse were excluded from the study although it has clinical and biochemical evidence of hypothyroidism.

Age, sex, height, and weight of controls and cases were recorded prior undergoing $\mathrm{F}$ wave study. Tests were performed by same electromyographer on same electromyograph at constant room temperature.

\section{EDX procedure}

All tests were done on RMS Portable Aleron Electromyograph machine. We adopted standard techniques by Preston DC and Shapiro BE for nerve conduction studies. ${ }^{7}$

Laboratory temperature was maintained constant throughout the procedures in all participants to avoid effect of temperature on $\mathrm{F}$ wave study variables. We performed median and ulnar $\mathrm{F}$ wave study bilaterally. Ten consecutive F-waves tracings were obtained by supramaximal stimulation of median and ulnar nerves distally at wrist. Active and reference electrode were placed as per belly-tendon montage settings of motor nerve conduction study. Low and high pass filters were set at $20 \mathrm{~Hz}$ and $3 \mathrm{KHz}$ respectively. Sweep speed and sensitivity was $10 \mathrm{~ms} / \mathrm{D}$ and $5 \mathrm{mV} / \mathrm{D}$ respectively. Miniature Compound muscle action potential identified at longer latency (F-waves) was identified. Out of ten F waves, one with minimum latency and another one with maximum latency were marked. Values were automatically generated for $\mathrm{F}$ wave minimum, maximum and mean latencies for median and ulnar nerves bilaterally.

\section{Statistical Analysis}

Data obtained was stored in Microsoft Excel spread sheet for further analysis. Statistical Package for Social Sciences (SPSS) 10.0 version was used for analysis. We used student unpaired t' test to compare statistically significant difference between cases and controls. Mean and standard deviation values of various anthropometric and $\mathrm{F}$ wave study variables were calculated and tabulated to show difference if any. $\mathrm{P}$ value $<0.05$ was considered statistically significant.

\section{Results}

In Table 1 comparison of anthropometric variables like age, height and weight between control and cases did not reveal any statistically significant difference ( $\mathrm{p}$ value >0.05). Thus controls were a perfect match for hypothyroid cases. Total 23 cases and 23 controls were evaluated using $\mathrm{F}$ wave study.

Table 1: Anthropometric profile of study population showing mean values with standard deviation and range in parenthesis

\begin{tabular}{|l|c|c|c|}
\hline \multicolumn{1}{|c|}{ Variables } & $\begin{array}{c}\text { Controls (n=23), } \\
\text { Male-09, Female-14 }\end{array}$ & $\begin{array}{c}\text { Cases }(\mathbf{n}=\mathbf{2 3}), \\
\text { Male-09, Female-14 }\end{array}$ & P value \\
\hline Age (years) & $\begin{array}{c}49 \pm 12, \\
\text { (Min-25, max-72) }\end{array}$ & $\begin{array}{c}50 \pm 13.6, \\
(\text { Min-23, max-75) }\end{array}$ & 0.874 \\
\hline $\begin{array}{l}\text { Height } \\
\text { (centimetres) }\end{array}$ & $\begin{array}{c}158.1 \pm 5.78, \\
(\text { Min-149, max-170) }\end{array}$ & $\begin{array}{c}157.4 \pm 5.71, \\
(\text { Min-150, max-170) }\end{array}$ & 0.664 \\
\hline Weight (Kgs) & $\begin{array}{c}60.26 \pm 9.49, \\
\text { (Min-49, max-72) }\end{array}$ & $\begin{array}{c}61.174 \pm 10.95, \\
\text { (Min-45, Maz-100) }\end{array}$ & 0.763 \\
\hline
\end{tabular}

(Note: $\mathrm{n}=$ number of participants, Kgs=kilograms, Min=Minimum, Max=Maximum)

In Table 2 comparison of $\mathrm{F}$ wave Minimum, Maximum and Mean latencies between cases and controls were shown. Statistically significant difference $P$ value $<0.05$ ) was observed in median $F$ wave minimum, maximum and mean latencies of control and cases. Whereas, difference was not significant in Ulnar $\mathrm{F}$ wave study variables $(\mathrm{p}$ value $>0.05$ ) 
Table 2: Comparison of $F$ wave latency parameters (F-Min, F-Max and F-Mean) among control and cases of study population

\begin{tabular}{|l|c|c|c|c|c|c|c|}
\hline \multicolumn{2}{|c|}{ Variables } & \multicolumn{2}{|c|}{ Controls (n=23) } & \multicolumn{2}{c|}{ Cases (n=23) } & \multicolumn{2}{c|}{$\begin{array}{c}\text { P value (between } \\
\text { control \& cases) }\end{array}$} \\
\cline { 3 - 9 } \multicolumn{2}{|c|}{} & Right & Left & Right & Left & Right & Left \\
\hline \multirow{2}{*}{$\begin{array}{l}\text { Median } \\
\text { F-wave } \\
\text { latency } \\
(\mathrm{ms})\end{array}$} & Min & $26.75 \pm 2.9$ & $26.7 \pm 2.8$ & $30.57 \pm 4.09$ & $30.1 \pm 3.65$ & $0.02^{*}$ & $0.001^{*}$ \\
\cline { 2 - 9 } & Max & $28.9 \pm 3.24$ & $28.9 \pm 2.9$ & $33.1 \pm 4.49$ & $32.55 \pm 5.17$ & $0.00072^{*}$ & $0.0052^{*}$ \\
\cline { 2 - 8 } $\begin{array}{l}\text { Ulnar F- } \\
\text { wave } \\
\text { latency } \\
(\mathrm{ms})\end{array}$ & $27.7 \pm 3.04$ & $27.72 \pm 2.9$ & $31.7 \pm 4.29$ & $31.28 \pm 4.32$ & $0.00075^{*}$ & $0.002^{*}$ \\
\cline { 2 - 8 } & Max & $27.3 \pm 2.8$ & $27.46 \pm 2.5$ & $27.4 \pm 3.87$ & $28.06 \pm 3.70$ & 0.9 & 0.53 \\
\cline { 2 - 8 } & Mean & $28.37 \pm 2.88$ & $28.61 \pm 3.1$ & $29.7 \pm 4.26$ & $30.52 \pm 4.47$ & 0.86 & 0.543 \\
\hline
\end{tabular}

(Note: $\mathrm{n}=$ number of participants, $\mathrm{ms}=$ milliseconds, Min=Minimum, Max=Maximum)

\section{Discussion}

Muscle and nerve damage in hypothyroidism is well established. Nerve conduction studies have been used to estimate electrophysiological prevalence of polyneuropathies, entrapment neuropathies and myopathies in hypothyroid patients. ${ }^{9}$ EDX studies often revealed neuromuscular slowing in hypothyroids. Latencies prolonged, Conduction velocities reduced had been reported in previous studies. A high ratio of polyneuropathy (20-70\%) associated with hypothyroidism has been reported and the mechanisms has been studied extensively. ${ }^{10}$ Segmental demyelination due to Schwann cell injury, Primary axonal degeneration has been shown electrophysiologically. ${ }^{11}$ Since the distal and sensory nerves are affected earlier, the most commonly involved nerves are the sural nerve and median nerve sensory fibres. CTS is caused by the deposition of mucinous material in the tissue surrounding the median nerve combined with mild hypothyroidism induced demyelinization. ${ }^{12}$

We observed that $\mathrm{F}$ wave minimum, maximum and mean latencies were prolonged in cases as compared to controls. Ulnar F wave latencies do not show significant abnormalities in cases as compared to controls. Further, we also observed that median latencies were prolonged as compared to ulnar latencies in same hand suggesting a reversal in ratio median Vs Ulnar F wave latencies. All these findings suggest distal median neuropathy probably at wrist. Our findings are corroborative with Gulbun Y et al who observed that median $\mathrm{F}$ wave latencies in hypothyroid were slightly prolonged although not statistically significant as compared to controls. He also reported median nerve most commonly affected with $50 \%$ patient had isolated CTS. ${ }^{6}$ Although comparison tests are most frequently used to screen median neuropathy at wrist; $\mathrm{F}$ wave study may be used as an EDX tool to rule out CTS in hypothyroid patients.

\section{Conclusion}

Present study revealed that median nerve abnormalities are most frequently evidenced in hypothyroid patients and same may be detected effectively using $\mathrm{F}$ wave study alone independent of other routine nerve conduction studies. $F$ wave (Median:Ulnar) min latency ratio reversal may be used to detect Median neuropathy at wrist in hypothyroid cases.

\section{References}

1. Abend W K, Tyler H R. Thyroid disease and the nervous system. Ed: Aminof JM, Neurology and General Medicine. 18:333-347, Churchill Livingstone, New York, 1995.

2. Duyff R D., Bosh J V., Laman D M., Potter van Loon BJ. Linssen HJPW. Neuromuscular findings in thyroid dysfunctions: a prospective clinical and electrodiagnostic study. J Neurol Neurosurg Phychiatry 2000;68:750-5.

3. Ettore B, Maria LD, Graziella B,Vittorio C, Felice P,Maurizio C, Michele Z. Hypothyroidism and polyneuropathy. Journal of Neurol Neurosurg Psychiatry 1989;52:1420-3.

4. Ladenson P W, Stakes J W, Ridgway C E. Reversible alteration of the visual evoked potential in hypothyroidism. The Am J Med 1984;77:1010-4.

5. Palumbo C F, Szabo R M, Olmsted S L, Sacramento C A. The effect of hypothyroidism and thyroid replacement on the development of carpal tunnel syndrome. J Hand Surgery 2000;25(4):734-9.

6. Gülbün Y, Geysu K, Tülin T, Önder U, Gülseren A. Nerve Conduction Studies, SEP and Blink Reflex Studies in Recently Diagnosed, Untreated Thyroid Disease Patients. Journal of Neurological Sciences [Turkish] 2007;24(1)\#10:7-15.

7. Preston DC, Shapiro BE. Late responses. In: Electromyography and Neuromuscular Disorders. Boston: Butterworth-Heinemann;1998:47-58.

8. Hamilton TE, Davis S, Onstad L, Kopecky KJ. Thyrotropin levels in a population with no clinical, autoantibody, or ultrasonographic evidence of thyroid disease: implications for the diagnosis of subclinical hypothyroidism. J Clin Endocrinol Metab 2008;93:122430.

9. Cruz M W, Mauro T, Mário V, Sérgio A, P. Novis. Electroneuromyography and neuromuscular findings in 
16 primary hypothyroidism patients. Arq. NeuroPsiquiatr.1996;54 (1):63-5.

10. Begni E., Deledovici M., Bogliun G., Crespi V., Paleari F., Gamba P., Capra M., Zarrelli .: Hypothyroidism and polyneuropathy. J Neurol Neurosurgy Phychiatry 1989;52:1420-3.

11. Nemni R., Bottacchi E., Fazio R., Mamoli A., Corbo M., Camerlingo M., Galardi G., Erenbourg L., Canal N.

Polyneuropathy in hypothyroidism: clinical,

electrophysiological and morphological findings in four cases. J Neurol Neurosurg Phychiatry 1987,50:1454-60.

12. Khedr E.M., El Toony L.F., Tarkhan M.N., Abdella G. Peripheral and Central Nervous System Alterations in Hypothyroidism: Electrophysiological Findings.

Neuropsychobiolog 2000, 41 (2):88-94. 